\title{
On the Amendments of Test Syllabus for Practical English Test for Colleges and the Impacts of the Amendments on the Reform of English Teaching in Vocational Colleges Chen Ping \\ ${ }^{1}$ Primary Educational Dept., Wuhan City Vocational College, Wuhan, Hubei, 430067 1255002145@qq.com
}

Keywords: Test Syllabus for Practical English Test for Colleges, English teaching in vocational colleges Positive impacts

\begin{abstract}
Practical English Test for Colleges has recently revised the Test Syllabus for Practical English Test for Colleges. In this paper, The author attempts to analyze the changes in the syllabus, including the question types, the quantity, the vocabulary as well as the validity. Then three aspects are discussed with respect to the positive influences of amendments of the Test Syllabus for the English teaching in colleges, including the cultivation of core English skills in vocational colleges and the creation of the teaching resources as well as the fusion of teaching and certificates.
\end{abstract}

\section{Introduction}

Practical English Test For Colleges (hereinafter referred to as PRETCO) is the kind of examination with the intention of measuring and evaluating college students' English ability in Higher Vocational Colleges. To implement the "national medium and long-term educational reform and development plan (2010 - 2020)", to promote and to deepen higher vocational education, and junior college education, to grasp the service development, to promote the employment ideas of running schools, to further implement the spirit of the Ministry of Education under the new situation of Vocational Education in English teaching and testing, to adapt to the requirements of the new situation higher vocational teaching, the commission for the Practical English Test for Colleges have decided to carry out appropriate amendments to the examination syllabus and examination papers, in order to be more scientific and objective to evaluate Higher Vocational Colleges Students’ English practical skills.

\section{An Interpretation on the reform of the syllabus of High school English application ability examination}

PRETCO has been appropriately adjusted in such areas as test items, the quantity and the vocabulary.

On the whole, the new syllabus has merely been properly adjusted, maintaining the basic framework design of the original papers. Having retained the 5 parts of objective tests and subjective combination. Besides, such comprehensive language skills as reading, listening speaking writing and translation have been tested based on rudimentary language knowledge assessment, there appeared also a slight revision on both the topic and content.

\section{1). Changes in the Amount of Examination Questions}

The amount of examination questions is manifested in Structure in Part II and Translation in Part IV. We can see clearly that The scope of choice has been greatly diminished. The options between the degree of distinction is more obvious.

\section{2). Changes in Question Types}

In Listening Comprehension a item is added as follows:

Section D. 
Directions: This section is to test your ability to comprehend short passages. You will hear a recorded passage. After that you will hear five questions. Bothe passage and the questions will be read two times. When you hear a question, you should complete the answer to it with a word or a short phrase(in no more than 3 words). The questions and incomplete answer are printed in your test paper. You should write your answer on the Answer Sheet correspondingly. Now listen to the passage.

Practicality can apparently be seen in this section.

\section{3). Changes in Vocabulary}

The new syllabus has adjusted the ratio of daily social vocabulary and that of common occupation.

The utility of vocabulary is an important part in the application of language. In order to better reflect the examinee by the mastering of the occupational English skills, to reflect the teaching requirements of higher occupation English course in the new period and the needs of society, the new syllabus has appropriately increased the proportion of common occupational vocabulary, the compilation of the "College English Test vocabulary" make the main basis for the exam. In addition, the "practical English skills table" has also been formulated to define the scope of practical skills examination.

The new syllabus provides "phrase table", "classified glossary", "prefix and suffix table" and "abbreviation" as appendices.

\section{4). Changes in Reliability and Validity}

The reliability and validity are the two most critical and most reliable evaluation indices in language testing. Reliability refers to the dependability and stability of the results of a certain examination, that is, the test results of the identical examinee should be consistent when the candidate has sat for the test repeatedly under the same conditions; whereas by "validity" we mean whether or not the specific inference drawn from the test scores is reasonable, meaningful, or effective. ( American Psychological Association 1985: 9)

Both are conflicting in nature. In general, the highly objective items, ie. multiple-choice questions tend to have high reliability, and therefore easy to operate, but the validity is not so high; and subjective items have high validity, but the credibility may not be so high, and also difficult to operate, thus more time-consuming and laborious. Therefore, in modern language tests, especially the large-scale test, with the aim to ensure the reliability and accuracy of the examination, a best balance point giving consideration to both aspects are often found between reliability and validity (or between subjective and objective questions) .

Training students to make full use of network, to absorb and integrate new knowledge and to build up their own new knowledge system on the basis of the original knowledge system.

Higher vocational English teaching should strictly implement the national education policy of "application as the sole purpose", follow the "actual, practical, pragmatic" principle, to be students-oriented, for practical purposes, in the English basic knowledge and basic skills teaching, control transmission "degree", will form an organic whole by combining basic language abilities and communicative ability training, so as to promote the basic English teaching to professional English teaching, and ultimately realize the transformation the overall integrated application ability. As a result, satisfying the demand for higher vocational talents by the development of society and economy.

\section{Integration of Accumulated Test and Occupation Qualification Certificate}

In the conventional teaching in English application ability examination and occupation qualification certificate types, contents and English teaching content of organic integration, thus, teaching college English test, English test, industry skills certificate and teaching of mutual integration, mutual promotion, implementation of "promoting teaching and learning through exams, and promoting construction with tests, to promote reform through competition of the original objective of reform", while achieving higher vocational education "course certificate 
integration” teaching characteristics. It will play the role of examination on the teaching reform of the positive reverse-guiding effect.

\section{Conclusion}

PRETCO examination and the higher vocational English teaching has always been closely interrelated with one another, coordinate reform of Higher Vocational English teaching, revision of the high school English application ability examination outline of the reform and innovation of Higher Vocational English teaching idea, teaching content and teaching method has important directive significance. In the optimization of talents training mode in the process, teachers should emphasize the training of students' English comprehensive application ability, professional ability and practice ability, should according to the feedback information timely examination of teaching reform and adjustment to effectively enhance the make, students' English application ability and the employment competitive power. So as To achieve new breakthroughs in reform of Higher Vocational English teaching in essence.

\section{References}

[1] The Ministry of Education of the People's Republic of China. Higher School English Application Ability Examination Syllabus (M). Beijing: Higher Education Press, 2014

[2] The Ministry of Education of the People's Republic of China[M]. The Basic Requirements for Education in English Teaching in Higher Vocational Colleges. Beijing: Higher Education Press, 2000

[3] Liu Runqing, et al. Chinese College Foreign Language Teaching Reform of Foreign Language Teaching - A Research on Present situation and Developmental Strategy [M] Beijing: Foreign Language Teaching and Research Press, 2003

[4] Duan Shaomin [5] A Lecture on "PRETCO”, Huanggang Normal University, Hubei Prov. Jan, 2014. 